\title{
Seaweeds for umami flavour in the New Nordic Cuisine
}

\author{
Ole G Mouritsen ${ }^{1,2^{*}}$, Lars Williams ${ }^{2,3}$, Rasmus Bjerregaard ${ }^{4}$ and Lars Duelund ${ }^{1}$
}

\begin{abstract}
Use of the term 'umami' for the fifth basic taste and for describing the sensation of deliciousness is finding its way into Western cuisine. The unique molecular mechanism behind umami sensation is now partly understood as an allosteric action of glutamate and certain 5'-ribonucleotides on the umami receptors. Chefs have started using this understanding to create dishes with delicious taste by adding old and new ingredients that enhance umami. In this paper, we take as our starting point the traditional Japanese soup broth dashi as the 'mother' of umami and demonstrate how dashi can be prepared from local, Nordic seaweeds, in particular the large brown seaweed sugar kelp (Saccharina latissima) and the red seaweed dulse (Palmaria palmata), possibly combined with bacon, chicken meat or dried mushrooms to provide synergy in the umami taste. Optimal conditions are determined for dashi extraction from these seaweeds, and the corresponding glutamate, aspartate and alaninate contents are determined quantitatively and compared with Japanese dashi extracted from the brown seaweed konbu (Saccharina japonica). Dulse and dashi from dulse are proposed as promising novel ingredients in the New Nordic Cuisine to infuse a range of different dishes with umami taste, such as ice cream, fresh cheese and bread.
\end{abstract}

Keywords: umami, seaweed, dashi, glutamate, kelp, dulse, New Nordic Cuisine

\section{Authors' summary for chefs}

Herein we review the concept of umami and deliciousness in a historical context and describe recent advances in the scientific understanding of the sensory perception of umami and the involved taste receptors. The primary stimulatory agent in umami is the chemical compound glutamate, which is found in large amounts in the Japanese seaweed konbu, which is used to prepare the soup broth dashi. We have explored the potential of local Nordic seaweeds, in particular sugar kelp and dulse, for dashi production and have discovered that dulse is high in free glutamate and hence a good candidate for umami flavouring. We describe methods by which to optimise the umami flavour using sous-vide techniques for extraction of the seaweeds, and we demonstrate how dulse dashi can be used in concrete recipes for ice cream, fresh cheese and sourdough bread.

\footnotetext{
* Correspondence: ogm@memphys.sdu.dk

1 MEMPHYS, Center for Biomembrane Physics, Department of Physics, Chemistry, and Pharmacy, University of Southern Denmark, Campusvej 55, DK-5230 Odense M, Denmark, ogm@memphys.sdu.dk

Full list of author information is available at the end of the article
}

\section{Background}

Although umami was suggested as a basic taste in 1908 by the Japanese chemist Kikunae Ikeda [1], umami only caught on very slowly in the Western world [2-5]. Being a verbal construction to describe the essence of delicious taste ('umai' (旨い) is delicious, and 'mi' (味) is essence, inner being or taste), the term 'umami' was coined by Ikeda to signify a unique and savoury taste sensation that should be ranked as the fifth basic taste along with the four classical basic taste modalities: sour, sweet, salty and bitter. In the past couple of decades, along with the globalisation of the Asian kitchen, and in particular the Japanese kitchen, umami is being used more commonly in a culinary context among chefs $[6,7]$ and food scientists [8]. The term has now entered the diverse world of cooking recipes and has been the main topic of a couple of cookbooks $[9,10]$ and most recently a popular science book [11].

Ikeda based his suggestion of umami as a specific taste on the discovery of a particular substance, monosodium glutamate (MSG), which he found in large quantities in free chemical form in one of the key ingredients that enters dashi, the soup stock behind all Japanese soups. 
Dashi is made by a warm extract of the large brown Japanese seaweed konbu (Saccharina japonica). This extract is called konbu dashi. To the konbu dashi is then added a particular, highly processed fish product, katsuobushi, leading to the so-called first dashi (ichiban dashi). Ikeda discovered that konbu contains about 2 to $3 \mathrm{~g}$ of free MSG per $100 \mathrm{~g}$ dry weight of konbu [1]. Whereas a lot of processed foods, in particular fermented products, can contain as much MSG as, and even more than, konbu [3,12-16], no other unprocessed, raw organic material is known to contain more free MSG than konbu. In addition to linking MSG to umami, Ikeda immediately realised the technological importance of his discovery as a means to produce artificial flavouring agents to foodstuff, leading the way to the establishment of the international company Ajinomoto (Tokyo, Japan) [17]. MSG is now used across the world as a flavouring enhancer, potentiator and additive in a wide variety of foodstuff [14]. In Europe, it has to be declared as E621 on food product labels.

There are several reasons for the slow acceptance of umami as a basic taste in the Western world. First, in contrast to Japanese cuisine, there is no single common ingredient in Western cuisines that provides as clean a sensation of umami as dashi, whereas Western cuisine has kitchen salt (sodium chloride) for salty, ordinary table sugar (sucrose) for sweet, quinine for bitter and acid for sour. Second, cultural differences imply fundamental differences in taste description and codability of taste [18]. Third, the taste sensation of pure MSG appears to be different in different individuals, probably because umami interacts strongly with sweet and salty $[19,20]$. This has led to confusion regarding MSG's being the source of a unique taste or simply a taste enhancer [21]. Fourth, a shear resistance to accept a new basic taste without a scientifically established sensational physiological basis probably also has played a role, certainly among food scientists and neurophysiologists.

A breakthrough came in 2000 when the first umami receptor was discovered [22]: the metabotropic glutamate receptor taste-mGluR4, which is a special dimeric G protein-coupled receptor [23] located in the membranes of the taste cells in the taste buds. Taste-mGluR4 is a truncated version of the well-known glutamate receptor mGluR4 in the brain, and it is selectively sensitive to L-glutamate. Since then, two other umami receptors have been found: T1R1/T1R3 [24,25] and a special mGlu receptor [26] that is related to the brain glutamate receptor mGluR1. It remains unclear whether the different umami receptors use different signalling pathways $[27,28]$.

The T1R1/T1R3 receptor is particularly interesting for an informed, molecularly based use of umami in the kitchen. In contrast to taste-mGluR4, which is sensitive only to L-glutamate, T1R1/T1R3 is also strongly stimulated by certain 5 -ribonucleotides, in particular inosinate (inosine-5'-monophosphate, IMP) and guanylate (guanosine-5'-monophosphate, GMP), which in a synergistic fashion potentiate the receptor's sensitivity to glutamate. This type of synergy in umami taste has been known phenomenologically for centuries in Japanese cuisine, and the first scientific basis for it was provided in 1957 by the Japanese chemist Akira Kuninaka [29]. Building on earlier work by Shintaro Kodama [30], who had found inosinate in katsuobushi, Kuninaka discovered that guanylate from dried shiitake mushrooms or inosinate from katsuobushi enter a synergistic relationship with glutamate from konbu. These synergies underlie classic preparations of dashi [15]. The molecular basis for the synergy in umami sensation has recently been revealed as a cooperative, allosteric binding of glutamate and ribonucleotides on the Venus flytrap motif on the T1R1 part of the T1R1/T1R3 receptor complex ([31] and $\mathrm{H}$ Khandelia and OG Mouritsen, unpublished data). Umami also enters an interaction with other tastes, in particular sweet and salty but also bitter, and a particularly complex relationship has been found between the umami receptor and the receptors for sweet and bitter [32]. In addition to glutamate, L-aspartate (monosodium aspartate, MSA) has also been associated with umami, but with much less potency and a still unknown sensory mechanism $[19,25]$.

Although in a much less pure form than in Japanese cuisine, umami also plays a key role in Western cuisine [11]. Many types of food contain large natural amounts of free MSG. The most well-known are Marmite, fish sauces, mature hard cheeses such as Parmesan cheese, blue cheeses, sun-dried tomatoes, anchovy paste, soy sauce, cured ham and so on. Similarly, synergy in umami sensation is used extensively in Western food pairing, such as tomatoes with anchovies, vegetables with meat, eggs with bacon, green peas with scallops, and so on.

The outline of the remaining part of the paper is as follows. First, we describe how dashi traditionally is made from konbu, then we move on to introduce some Nordic seaweed species that are candidates for dashi production. The main core of the paper that follows those sections describes improved methods of dashi production, including in particular production in controlled temperature conditions. Data regarding the content of free glutamate and other amino acids in different seaweed extracts is presented. Moreover, three concrete recipes are provided for dishes that take advantage of the dashi and umami flavours from the red seaweed species dulse that turns out to release large amounts of free glutamate. In the "Discussion" and "Conclusion" sections, we highlight the potential of using seaweed species from local Nordic waters in the New Nordic Cuisine. 


\section{Dashi from seaweeds}

Classic Japanese cuisine [33] revolves around dashi made from konbu and katsuobushi. In the strictly vegetarian temple kitchen, shōjin ryōri, also known as 'the enlightened kitchen' [34], deriving from 12th-century Japan, katsuobushi is replaced by dried shiitake. Konbu provides glutamate and shiitake provides guanylate to replace inosinate from katsuobushi. The synergetic action in umami is even stronger in the pairing of glutamate with guanylate than with inosinate $[31,35]$.

There are several variants of konbu, all of which belong to the algal order Laminariales, with Saccharina japonica being the most commonly used species for dashi. Konbu hence belongs to the same genus as sugar kelp (Saccharina latissima). The blades of konbu can grow to be several metres long and have a maximum width of 10 to $30 \mathrm{~cm}$. Most of the konbu on the world market for human consumption is farmed at lines in the seas around Japan and China. After harvest, konbu is sun-dried and the best quality konbu is aged in cellars (kuragakoi) for from one to ten years, with the typical ageing period being two years. During ageing, the seaweed matures and obtains a milder flavour and a less strong taste and smell of the sea. The umami flavour in dashi made from aged and matured konbu appears to stand out more clearly.

Konbu contains large amounts of free amino acids, of which $80 \%$ to $90 \%$ are glutamic acid in the form of MSG [3]. Other important free amino acids are alanine and proline, which impart a sweet taste to the seaweed. Konbu does not contain any of the 5'-ribonucleotides that enter synergistically with glutamate in umami. Often some of the free MSG precipitates together with salt and mannitol to form a white layer on the surface of the dried and aged konbu blades. This layer should not be removed before the dashi is extracted from the konbu, because it dissolves readily in water and provides a combination of flavours: umami, salty and sweet. Mannitol is a sweet-tasting sugar alcohol which has about $60 \%$ of the relative sweetness of table sugar (sucrose). Mannitol is often found in the Saccharina family, in particularly large amounts in sugar kelp (hence its name). Konbu contains 2 to $3 \mathrm{~g}$ of free MSG per $100 \mathrm{~g}$ dry weight. With the exception of the pulp of mature tomatoes [36], konbu is possibly the kind of foodstuff that, with the least amount of processing, develops free glutamate in any appreciable amounts.

Of the many different variants of Japanese konbu, makonbu, rausu-konbu and rishiri-konbu are considered to be the best for extraction to dashi [10], and they lead to a very light dashi with a mild and somewhat complex taste. Ma-konbu is the konbu with the largest amount of free glutamate, 3,200 mg/100 g, whereas rausu-konbu has 2,200 mg/100 $\mathrm{g}$ and rishiri-konbu has 2,000 mg/100 g. The lower-quality hidaka-konbu has $1,300 \mathrm{mg} / 100 \mathrm{~g}$ $[10,12]$. The red seaweed laver (Porphyra yezoensis) used to produce nori has comparable amounts $(1,378 \mathrm{mg} /$ $100 \mathrm{~g}$ ), whereas wakame (Undaria pinnatifida) has very little $(9 \mathrm{mg} / 100 \mathrm{~g})$ [12].

A remarkable feature of dried and aged konbu, as well as a number of other seaweeds, is that the free glutamate in the tissues of the seaweed can be transferred to water by a rather mild, warm extraction process solely involving water. Although there is a substantial variation in the way different chefs prepare konbu dashi, the recipes used generally prescribe soaking the dry konbu in water at room temperature (typically using $10 \mathrm{~g}$ of dry konbu per litre of water) for about half an hour, heating it in an open pan to just below the water boiling point at $100^{\circ} \mathrm{C}$ and then quickly removing the konbu from the water before bitter-tasting compounds seep out. During this procedure, only a relatively small amount of the total free glutamate is released into the water. A typical konbu dashi or ichiban dashi prepared using the traditional Japanese recipe (K Ninomiya, unpublished data from the Umami Information Center, and [37]) contains about 20 to $30 \mathrm{mg}$ of glutamate per $100 \mathrm{~g}$ of aqueous dashi extract. The extraction process can be optimised by varying conditions such as extraction temperature and possibly the quality (hardness) of the water used for the extraction. We shall address the optimisation of dashi preparation in this paper and show that by extracting the seaweeds at a lower temperature but for a longer time, a much more flavourful dashi characterised by significantly higher levels of glutamate as well as aspartate can be obtained.

Although konbu is the kind of seaweed that contains the largest percentage of free glutamate, other seaweeds can also provide some umami flavour despite their smaller glutamate content. Laver (Porphyra spp.) that is used to produce the paper-thin nori sheets well-known from maki-zushi [38] contains rather large amounts of free glutamate [12] in addition to some inosinate and guanylate, which enhances the umami flavour in sushi dishes. In fact, nori is the only kind of seaweed that contributes to both basic (glutamate) and synergetic (nucleotides) umami flavour.

Until now, little work has been reported on the use of seaweeds other than konbu for dashi preparations, although it is well-known that seaweeds in general impart delicious flavours to food $[39,40]$. Moreover, the use of seaweeds for human consumption is little developed in the Western world [41]. To investigate the potential of using local seaweeds from the waters around the Nordic countries for dashi preparations and umami flavouring, we have undertaken quantitative scientific and qualitative 
gastronomic investigations of dashi extracts from a brown seaweed, sugar kelp (Saccharina latissima), and a red seaweed, dulse (Palmaria palmata). Some preliminary work has also been done on the red seaweed graceful red weed (Gracilaria verrucosa). For comparison, we have simultaneously studied classic dashi prepared from various qualities of Japanese konbu (Saccharina japonica). Our investigations can be seen as an attempt to explore the gastronomic potential of local seaweeds [42] for use in the New Nordic Cuisine $[43,44]$.

\section{The seaweeds}

\section{Sugar kelp (Saccharina latissima)}

The large, metre-long, brown seaweed (kelp) of the order Laminariales, sugar kelp (Saccharina latissima) is rich in iodine and minerals, in particular calcium, potassium, manganese and iron. It is very common in the sublittoral zones of the cold seas of the North Atlantic Ocean, and it has a strong flavour of the ocean. Its name derives from its distinct sweet taste caused by large amounts of the sugar alcohol mannitol. Sugar kelp can release significant amounts of extracellular polysaccharides, such as alginates, that easily seep out in water extracts, making these undesirably viscous for most gastronomical uses. The tissues of sugar kelp are tougher than those of konbu.

In the present work, we used sugar kelp farmed in Denmark. Both young and old specimens are harvested, and before use for dashi they are all subject to drying. Some samples were also stored and aged for a period of time before use. Specimens of dried, farmed sugar kelp are shown in Figure 1.

\section{Dulse (Palmaria palmata)}

Dulse (Palmaria palmata) is a red, intertidal seaweed well-known in the traditional cuisines of Ireland,
Scotland and Iceland, as well as along the coasts of North America. It is common in the Atlantic Ocean, where it grows to a size of up to $50 \mathrm{~cm}$. It has thin and delicate purple fronds with simpler polysaccharides than those found in the brown seaweeds, providing dulse with a more delicate flavour and soft texture. When dried, dulse develops hints of liquorice and smoke, and when toasted it has a nutty taste. Although dulse appears to be one of the seaweeds with the more interesting potential for gastronomical applications, it is surprisingly little used in modern cuisine.

In the present work, we used a variety of different supplies of dulse. Some were harvested in the wild in Iceland, and some were farmed in Denmark. All samples were dried before use. A specimen of dried, farmed dulse is shown in Figure 2. This particular specimen has an almost isotropic shape due to its being grown freely in a pool with constantly moving and swirling water. This is in contrast to dulse naturally grown by being anchored on a substrate at the bottom of the sea, which usually leads to a directional, treelike structure of the shape of a hand, as suggested by the Latin name palmata.

\section{Graceful red weed (Gracilaria verrucosa)}

This red and stringy seaweed, also called 'sea moss' because of its thread-thin fronds, has not been used to date in Western cuisine. It is traditionally used as a sea vegetable, for example, in Hawaii and Japan, where it is called ogonori. Gracilaria is a rich source of agar that is used as a thickening agent. In recent years, it has made its way into the Nordic waters, where it is considered one of the invasive species that threatens domestic marine life. In the present work, we used Gracilaria farmed in Denmark, and all samples were dried before use.

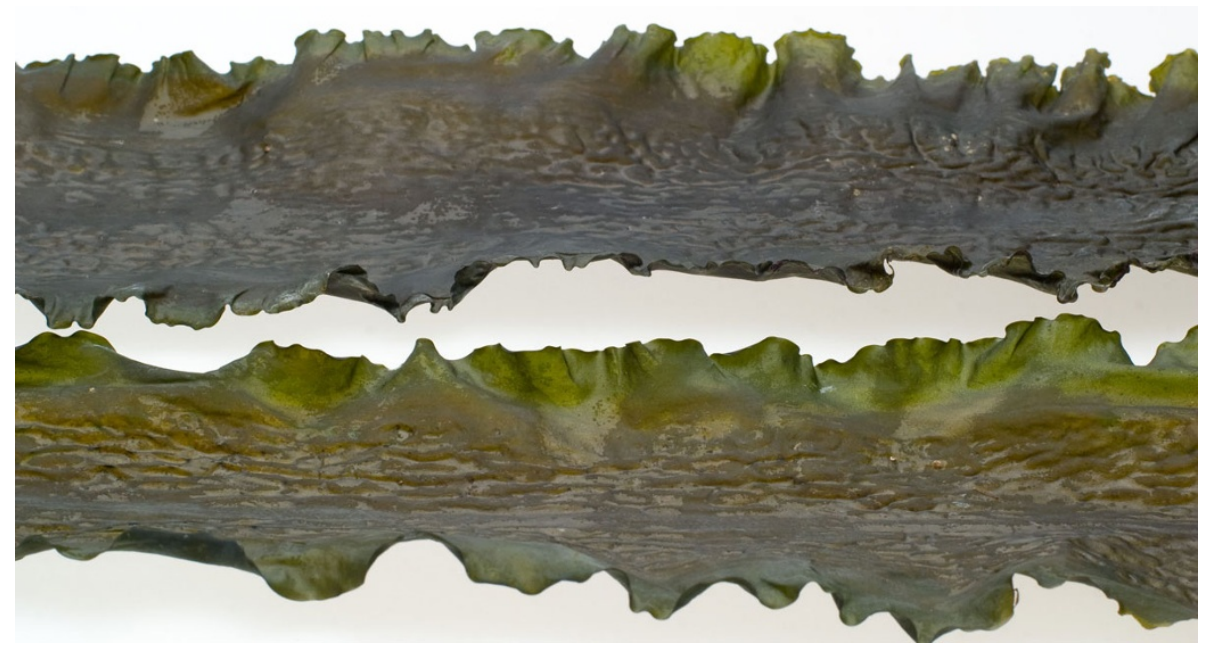

Figure 1 Dried sugar kelp (Saccharina latissima) farmed in Horsens, Denmark. (Photography: Jonas Drotner Mouritsen.) 


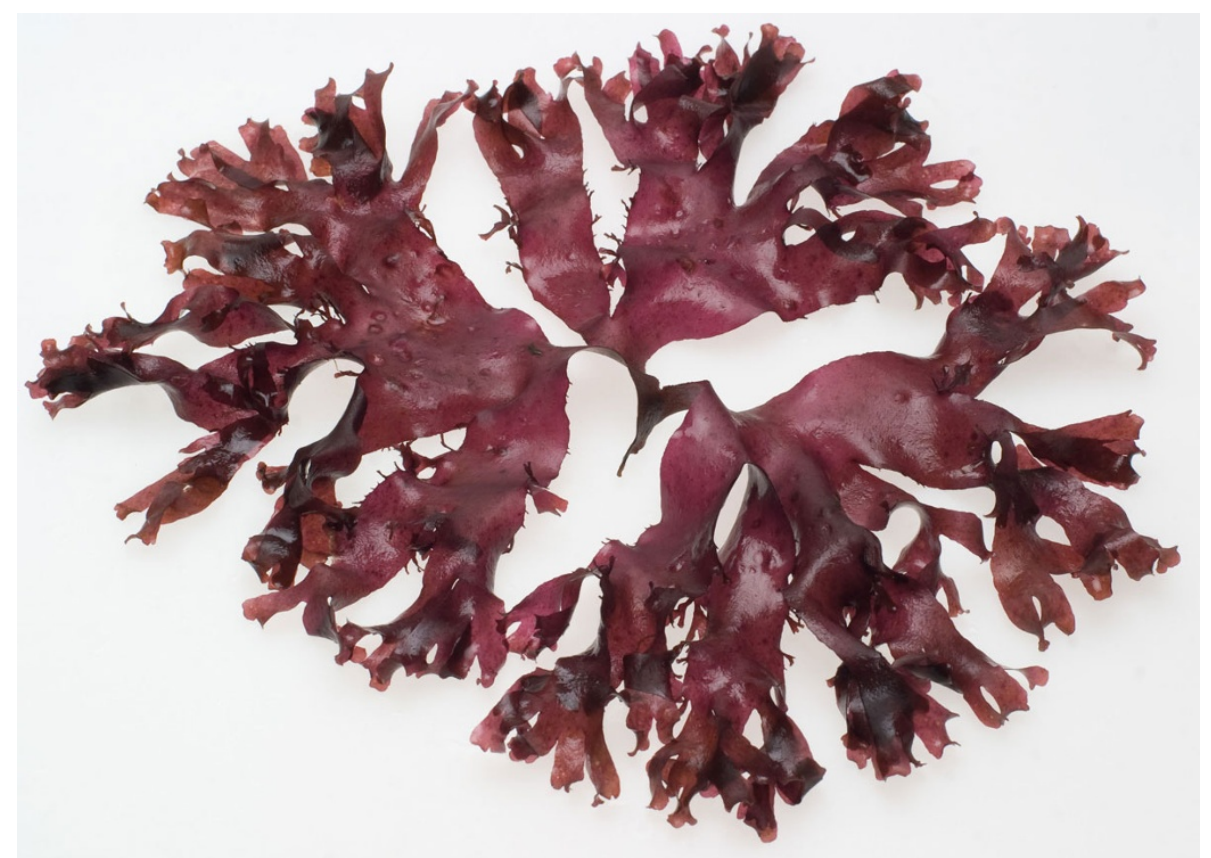

Figure 2 Dried dulse (Palmaria palmata) farmed in Horsens, Denmark. (Photography: Jonas Drotner Mouritsen.).

\section{Konbu (Saccharina japonica)}

Konbu is a large brown seaweed that is farmed in large quantities in China and Japan, amongst other countries. In these Asian countries it is a common staple in traditional cuisine as a sea vegetable and a source for dashi, and it is also used in a wide range of processed konbu products. Konbu is appreciated for its mild and umami flavour and has an interesting and soft texture, despite the considerable thickness of its fronds. Similarly to sugar kelp, konbu is high in iodine. It secretes much less polysaccharide than sugar kelp when extracted from water, and the resulting dashi is light in colour with a fluidity similar to that of pure water. In the present work, we used two commercial supplies of dried Japanese konbu of two distinct qualities: a first-quality rausukonbu and a second-quality hidaka-konbu.

\section{Results}

The dashi from the seaweeds is prepared as described in 'Materials and methods'. Figure 3 shows photographic images of samples of dashi prepared from, respectively, konbu (konbu dashi), konbu and katsuobushi (ichiban dashi) and dulse (dulse dashi). The konbu dashi is very light in colour, the ichiban dashi is darker because of colouring from the fermented katsuobushi and the dulse dashi has a light purple colour.

The colours and flavours of the different types of dashi vary quite significantly. The colour and flavour of the sugar kelp dashi differed in relation to the age of the seaweeds and whether they were in a sorus stage.
The sorus contains the sporophylls and is the reproductive organ of the seaweed. Dashi prepared from sorus had far less flavour and were lighter in colour than those not in a reproductive cycle. All of the sugar kelp dashi is viscous. With regard to the dulse, there is a distinct difference between dashi from fresher seaweed and that which has been aged. This is evident in the appearance of the original material. The aged seaweed precipitates more salts (including glutamate) on the surface of the fronds in a rather conspicuous manner, and the taste is far stronger and more complex. Therefore, we can conclude that this ageing process is critical for a superior taste and a method employed for producing high-quality konbu.

The difference in the dashi prepared from the two types of konbu is as visually dramatic as it is in taste. The hidaka-konbu produces a dashi with a somewhat greenish hue, with a smell evocative of the term 'sea vegetable'. The taste is briny, with a slight metallic vegetable tone. In contrast, the rausu-dashi is golden in colour and tastes almost like the chicken bouillon it resembles, very meaty and intense. This taste was amplified when we gently reduced the rausu-dashi in a dehydrator at $60^{\circ} \mathrm{C}$, and the stock eventually turned into crispy flakes, as shown in Figure 4. Biting in these flakes was almost as overpowering as biting into a bouillon cube. The konbu-dashi seemed to be the only dashi suitable for this process. The dehydrated dashi from the other types of seaweed became bitter, or unable to fully dry, and it remained sticky. 


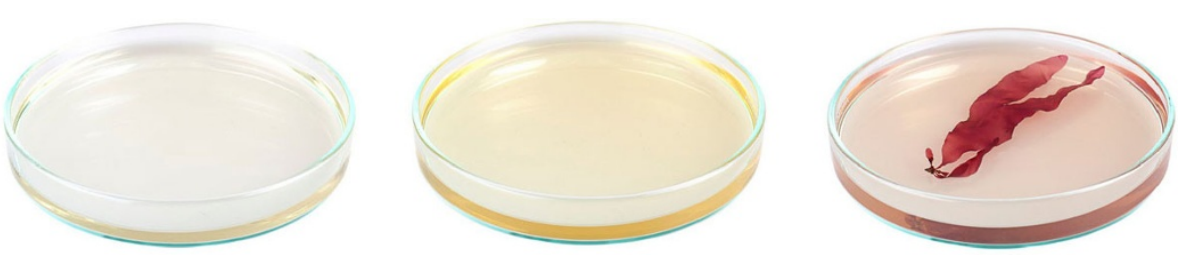

Figure 3 Dashi based on three different seaweed extracts. Left: Konbu dashi from Saccharina japonica. Middle: Traditional Japanese ichibandashi from konbu and katsuobushi. Right: Nordic dashi from dulse (Palmaria palmata). For illustration, a piece of dulse is left in the dulse dashi. (Photography: Jonas Drotner Mouritsen.).

The different dashi preparations made from the different samples of dried seaweeds were analysed for their full amino acid content and profile, with a focus on glutamate and aspartate, which provide umami flavour, and alaninate, which provides a sweet flavour. The results are shown in Table 1. Figure 5 shows the full amino acid profiles for two types of dashi made from rausukonbu and dulse, respectively. We shall return to a discussion of these profiles in the 'Discussion' section below and to a comparison of dashi made from different seaweeds as opposed to the use of different extraction techniques.

The data in Table 1 refer to extractions by the techniques introduced in this paper and described in 'Materials and methods'. It should be noted that the precise amount of amino acids can be very sample-dependent and that the error bars quoted in Table 1 reflect only the estimated uncertainties in the actual amino acid analysis. The data show that rausu-konbu releases very large amounts of free glutamate and aspartate, whereas the levels of alaninate are rather low. The hidaka-konbu provides for about half the amount of glutamate and aspartate compared to rausu-konbu. These differences in the umami-producing amino acids reflect the qualitative taste sensations described above and explain why rausukonbu is considered to be superior to hidaka-konbu for dashi production. In contrast to the differences in umami taste compounds, the two types of konbu release similar amounts of alaninate.

It turns out, somewhat surprisingly, that extraction temperatures of $60^{\circ} \mathrm{C}$ and $100^{\circ} \mathrm{C}$ led to similar results with respect to the concentrations of glutamate, aspartate and alaninate in konbu dashi. Also, the softness of the water seems to have had little influence on the concentration of the three amino acids in the dashi extracts studied.

Turning to the dashi prepared from sugar kelp, Table 1 shows that dashi from sugar kelp contains very little of any of the free amino acids analysed, and the results did not depend on whether we used extraction temperatures of $60^{\circ} \mathrm{C}$ or $100^{\circ} \mathrm{C}$. Additionally, the measured amounts are so low that we can find no discernible dependence on

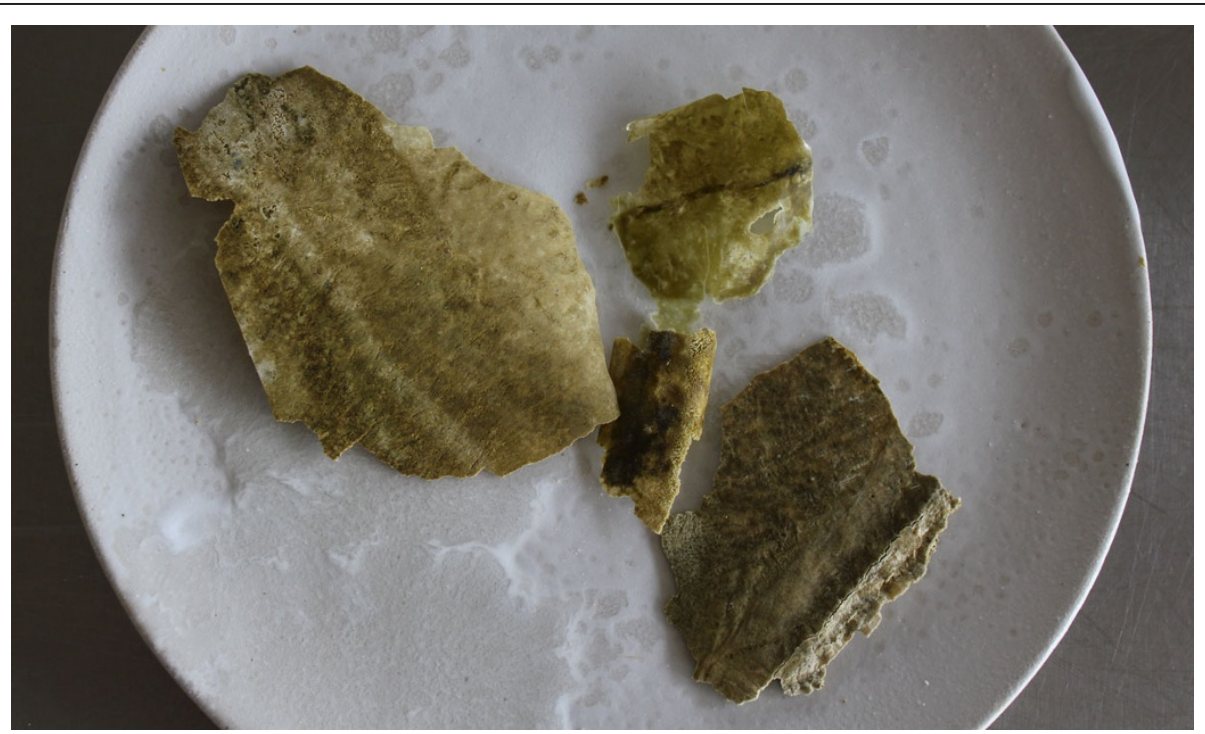

Figure 4 Kelp 'crisps' that are formed as flakes when dehydrating a dashi produced by extraction of rausu-konbu. (Photography: Lars Williams.). 
Table 1 Extraction of glutamate, aspartate and alaninate from dried seaweeds

\begin{tabular}{lccc}
\hline Seaweed & $\begin{array}{c}\text { Extracted glutamate } \\
(\mathbf{m g} / \mathbf{1 0 0} \mathbf{~ g})\end{array}$ & $\begin{array}{c}\text { Extracted } \\
\text { aspartate (mg/100 g) }\end{array}$ & $\begin{array}{c}\text { Extracted alaninate } \\
(\mathbf{m g} / \mathbf{1 0 0} \mathbf{~ g})\end{array}$ \\
\hline Rausu-konbu (farmed, Japanese) & $145 \pm 5$ & $85 \pm 15$ & $20 \pm 3$ \\
Hidaka-konbu (farmed, Japanese) & $70 \pm 15$ & $40 \pm 20$ & $20 \pm 10$ \\
Sugar kelp (farmed, Danish) & $3 \pm 3$ & $3 \pm 2$ & $7 \pm 4$ \\
Dulse (farmed, Danish) & $40 \pm 10$ & $27 \pm 8$ & $25 \pm 6$ \\
Dulse (wild, Icelandic) & $10 \pm 5$ & $11 \pm 2$ & $12 \pm 2$ \\
Graceful red weed (farmed, Danish) & 6 & 1 & 4 \\
\hline
\end{tabular}

All extractions are based on $10 \mathrm{~g}$ of dry seaweed in $500 \mathrm{ml}$ of water extracted over a period of 45 minutes in a vacuumed, sealed plastic bag placed in a water bath at the prescribed constant extraction temperature. The extracted amounts of amino acids refer to the concentrations measured in the specific aqueous extract. The concentrations quoted refer to the amino acids in their deprotonated form. The quoted error bars reflect the variation over two to five independent measurements (except for graceful red weed, for which only one measurement was performed). It should be noted that the precise amount of amino acids measured could be very sample-dependent and that the error bars quoted reflect only the estimated uncertainties in the actual amino acid analysis.

the age of the kelp, whether it was matured or not or whether it contained the sorus or not. It is possibly that sugar kelp grown under other nutritional conditions with more nitrogen may contain more glutamic acid and free glutamate than the sugar kelp used for the present study. As noted above, dashi from sugar kelp displays an undesirable viscous behaviour that makes it less suitable as a soup stock.

In contrast to sugar kelp, the data for the dulse dashi in Table 1 show that this red seaweed has an exceptionally good potential for umami flavour. The farmed Danish dulse releases significantly more glutamate and aspartate than the wild Icelandic dulse. In the case of the Icelandic dulse, we measured both young dulse and aged dulse, but found no significant differences in the amount of released amino acids. For none of the dulse samples studied are we able discern any variation in amino acid concentrations for the two different extraction temperatures. Table 1 shows that Gracilaria is a poor source of umami flavours, similar to farmed Danish sugar kelp.

\section{Examples of dishes flavoured by dulse}

In this section, we provide some specific recipes using dulse for flavouring dishes developed for the New

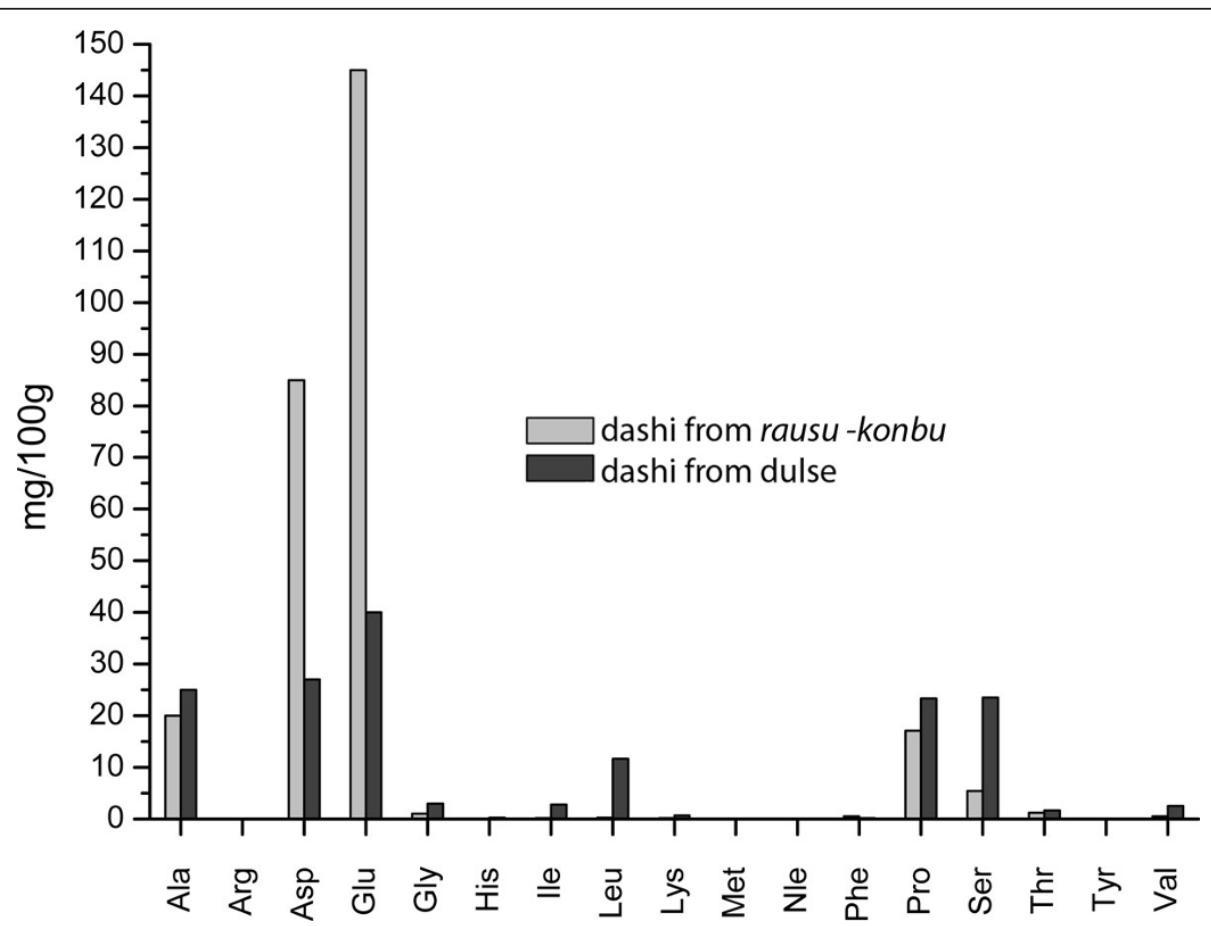

Figure 5 Amino acid profiles for two types of dashi made from rausu-konbu and dulse, respectively. Both types of dashi are based on 10 $\mathrm{g}$ of dry seaweed in $500 \mathrm{ml}$ of water extracted over a period of 45 minutes in a vacuumed, sealed plastic bag placed in a water bath at the prescribed constant extraction temperature. The extracted amounts of amino acids refer to the concentrations measured in the specific aqueous extract. The concentrations quoted refer to the amino acids in their deprotonated form. 
Nordic Cuisine. The recipes represent a range of novel experiments conducted at the Nordic Food Lab. Photographs of the resulting dishes are shown in Figure 6.

\section{Ice cream with dulse}

$600 \mathrm{~g}$ of dulse-infused milk (infuse at $20 \mathrm{~g}$ of dulse/ litre of milk)

$100 \mathrm{~g}$ of cream

$80 \mathrm{~g}$ of trimoline (inverted sugar syrup)

$35 \mathrm{~g}$ of sugar

$24 \mathrm{~g}$ of ColdSwell cornstarch (KMC, Brande, Denmark)

Place the dulse and milk in a plastic bag under vacuum and seal, leaving it in a refrigerator overnight to coldinfuse. Strain the dulse and blend it into a fine purée, and preserve to be added later. Dissolve the sugar and trimoline in a small amount of warmed milk. When cooled, add the milk to the rest of the components, mix thoroughly and freeze the mixture in Pacojet containers. Just before serving, the ice cream is prepared in the Pacojet by high-speed precision spinning and thin-layer shaving to produce a creamy consistency of the ice cream.

The dulse ice cream was conceived to demonstrate the culinary versatility of seaweed in an often unexpected fashion. We chose a low-fat base of almost all milk used, allowing the flavour to emerge. Although there was initial reluctance among some tasters to the idea of seaweed ice cream, the vast majority responded with satisfaction upon actually consuming the ice cream.

The colour of the dulse ice cream is a very pleasing light mauve. The flavour is delicate, light and floral. Some tasters have compared the dulse ice cream with Japanese green tea ice cream, which is indicative of a nuanced, acceptable flavour profile.

We also observed an improvement in texture of the dulse-infused ice cream, which is creamier and smoother than the same ice recipe without dulse. This change in texture is likely caused by the polysaccharides released from the dulse.

\section{Fresh cheese with dulse}

$1,250 \mathrm{~g}$ of dulse-infused milk (infuse at $20 \mathrm{~g}$ of dulse/litre of milk)

$60 \mathrm{~g}$ of cream

$25 \mathrm{~g}$ of buttermilk

$5 \mathrm{~g}$ of rennet

Place dulse and milk in a plastic bag under vacuum and seal, leaving it in a refrigerator overnight to coldinfuse. Strain the milk, heat it to $33^{\circ} \mathrm{C}$ and add the remaining ingredients, including the rennet. Pour the mixture into plastic containers, cover tightly and cook in an oven at $36^{\circ} \mathrm{C}$ for 45 minutes.

The result is a slightly acidic, fresh cheese with a light tofulike consistency. There is a bit more brininess and more of a rounder seaweed flavour than with the ice cream. Again, there is a desirable improvement in texture and a slightly more elastic, though very pleasant, mouthfeel. This more viscous texture is likely due to carrageenan released from the dulse, which also reduces the cooking time by half.

\section{Bread with dulse}

$2,500 \mathrm{~g}$ of ølandshvede flour, a speltlike wheat species that is high in gluten and protein (13.5\%)

$500 \mathrm{~g}$ of spelt flour

$2,200 \mathrm{~g}$ of dulse dash $i$, strained, dulse-minced and reserved

$200 \mathrm{~g}$ of sourdough starter

$50 \mathrm{~g}$ of fresh baker's yeast

$60 \mathrm{~g}$ of salt

Whisk dashi, starter, yeast and salt together. Add flour and mix at low speed for 5 minutes. Incorporate the minced dulse. Oil a suitable vessel, and proof in a $5^{\circ} \mathrm{C}$
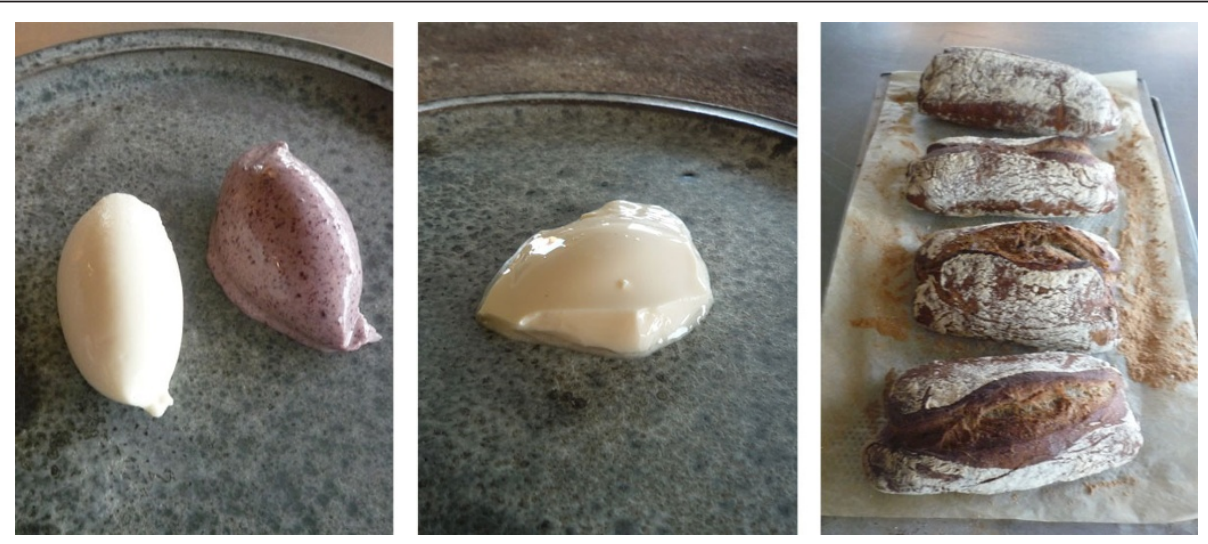

Figure 6 Examples of dishes flavoured with dulse. Left: Ice cream without and with dulse infusion. Middle: Fresh cheese infused with dulse. Right: Bread made from a sourdough infused with dulse. (Photography: Lars Williams.). 
refrigerator for 24 hours, folding every 8 hours. Shape and allow it to come to room temperature. Bake in an oven at $225^{\circ} \mathrm{C}$ for 45 minutes.

The dulse sourdough was considered to be a great success. The liquorice, almost fruity tones came forward and added a supportive savoury flavour. The tea tones steamed from a fresh piece of warm bream when torn apart. It was especially excellent with cheese, almost addictive according to many reports from tasters. The crumb seemed quite moist and had excellent texture. The mixing of the bread was quite different from normal, and some care had to be taken not to overmix the dough.

\section{Discussion}

The results presented herein provide some quantitative data for amino acid profiles in dashi prepared from Nordic seaweeds, which reveal their potential for providing umami taste. Clearly, the results show that among the studied species, dulse is a much more interesting candidate than sugar kelp and Gracilaria for umami flavouring and dashi. Moreover, the three recipes presented demonstrate in a concrete setting that dulse dashi has a versatile use in the kitchen.

To assess the relative potential of dulse in umami flavouring, we compared the amino acid composition of dashi prepared from dulse with classical dashi on the basis of Japanese konbu. This comparison is provided in Table 2, together with data for two types of chicken soup stock $[45,46]$. Caution should be exercised when comparing data for the same seaweed species from different sources, because the sample material can be vastly different and the methods of amino acid analysis used and reported in the literature can differ as well. The latter can be particularly troublesome for analysis of extracts of glutamate from brown seaweeds, because it is known that their alginate and salt contents can interfere with the derivation of the amino acids when using classic highperformance liquid chromatography (HPLC) methods [47]. Moreover, different workers have used different amounts of seaweed for their dashi preparations. In the present work, we used about twice the amount of dry seaweed per litre of water compared with many classic Japanese dashi recipes. Still, upon normalising to the same weight ratios, we generally found that the use of the extraction techniques described in the present paper released at least twice as much glutamate and aspartate and up to almost ten times as much alaninate compared to values reported in the literature for konbu (Table 2).

Notwithstanding the above-mentioned difficulties in comparing, on a quantitative basis, the amino acid contents in dashi quoted in reports from different workers, we can compare the contents in dashi which we have prepared in the present work using the same weight ratios for seaweed and water and applying the same preparation techniques. As seen in Table 2, we found that dashi prepared by our extraction technique has substantially more umami capacity than dashi prepared by the classic Japanese recipe, which typically involves cold soaking of the konbu for 30 to 60 minutes, followed by warm extraction in a pan and increasing the temperature to just below boiling, then immediately straining the extract. It is wellknown that keeping the konbu in the boiling dashi leads to an unpleasantly bitter flavour. More recently, the classic Japanese recipe has been optimised to provide a better flavour and a clearer dashi by heating the solution to only $60^{\circ} \mathrm{C}$ (as in the present work), but still in an open pan [37]. The many different recipes for preparing classical Japanese dashi probably reflect different preferences among the chefs with respect to the balance between bitter, sweet and umami notes of the extract. The comparison of data in Table 2 between dashi based on various seaweeds and traditional soup stock prepared from chicken meat and vegetables shows that seaweeds may be superior to these meatvegetable soups with respect to providing compounds that induce umami.

The taste of the dulse dashi is found to be more sweet and complex than traditional konbu dashi. Part of the explanation may be found in the differences in the full amino acid profiles shown in Figure 5. Compared to

Table 2 Comparison of amino acid contents in dashi and various soup stocks

\begin{tabular}{|c|c|c|c|}
\hline Dashi or soup stock & $\begin{array}{l}\text { Glutamic acid } \\
(\mathrm{mg} / 100 \mathrm{~g})\end{array}$ & $\begin{array}{c}\text { Aspartic acid } \\
(\mathrm{mg} / 100 \mathrm{~g})\end{array}$ & $\begin{array}{c}\text { Alanine } \\
(\mathrm{mg} / 100 \mathrm{~g})\end{array}$ \\
\hline Rishiri-konbu dashia & 22 & 16 & 1 \\
\hline Rausu-konbu dashi (traditional) ${ }^{\mathrm{b}}$ & 100 & 60 & 7 \\
\hline Rausu-konbu dashi (sous-vide) & 145 & 85 & 20 \\
\hline Ichiban dashic & 25 & 18 & 4 \\
\hline Dulse dashib & 40 & 27 & 25 \\
\hline Western chicken stock ${ }^{d}$ & 18 & 6 & 11 \\
\hline Chinese tang (chicken base) ${ }^{\mathrm{e}}$ & 14 & 4 & 8 \\
\hline
\end{tabular}

${ }^{a}$ Recipe: $1.8 \mathrm{~L}$ of water and $30 \mathrm{~g}$ of rishiri-konbu. The konbu is soaked in the water, placed in a pan and heated to $60^{\circ} \mathrm{C}$ for 1 hour ( $\mathrm{K}$ Ninomiya (personal communication) and [37]). ${ }^{b}$ This work. ${ }^{c} \mathrm{~K}$ Ninomiya (unpublished data from the Umami Information Center). ${ }^{\mathrm{d}}$ From [45]. ${ }^{\mathrm{e}} \mathrm{From}$ [46]. Note that the rausu dashi and the dulse dashi are prepared by using about twice as much seaweed per litre of water as that used for the rishiri dashi and ichiban dashi. 
konbu, dulse releases more of the sweet amino acids alanine, proline, glycine and serine. The dulse extracts also contain small amounts of the bitter-tasting amino acids such as isoleucine, leucine and valine, which may account for the more complex flavour of the dulse dashi. It is noteworthy that the farmed Danish dulse is a serious competitor with hidaka-konbu for umami flavour. One reason may be that the much thinner and delicate fronds of dulse are more susceptible to releasing their contents of free amino acids during extraction.

Often it is stated that the softness of water is important for dashi preparation [10]. This may be true for the total flavour of the extract, but we cannot discern any significant dependence on water hardness in terms of the actual amounts of free amino acids. Also, the amino acid contents and profiles did not depend on whether we used extraction temperatures of $60^{\circ} \mathrm{C}$ or $100^{\circ} \mathrm{C}$. Hence it is not bitter amino acids that cause the bitter taste often found in a dashi which has been prepared close to boiling.

We found that sugar kelp with and without sorus did not lead to a different dashi in terms of amino acid composition. Still, it is well-known that the sorus of some seaweeds can be more flavourful than the other parts of the fronds. This is recognised particularly in the case of the brown seaweed wakame (Undaria pinnatifida), in which the reproductive organs, the sporophylls (mekabu), are appreciated for their mouth-filling flavour, which might be caused by their higher fatty acid contents compared to the fronds.

Traditional Japanese dashi recipes prescribe addition of the prepared fish product katsuobushi to the seaweed extract to provide for synergy compounds, specifically inosinate. In an attempt to find a suitable alternative to katsubushi to finish a dashi from dulse, we considered typical cured products that Scandinavians consume on a normal basis. Bacon was a delicious-sounding first thought. Pork bacon contains high levels of inosinate and glutamate [12] and would be an ideal starting point. The smokiness of the bacon, combined with the tealike dulse dashi, accounted for a surprisingly complex flavour profile. There was an obvious meatier taste, but it was very well balanced with a floral sweetness and slight mineral notes. We declared it a consummate success. We have also experimented with other sources to provide synergetic compounds for umami in Nordic dashi. Specifically, we have found that the inosinate contents in dried and salted chicken meat enhance the umami of the dulse dashi to some degree, whereas dried local mushrooms such as champignon seemingly contain too little guanylate to furnish anything interesting to pursue.

\section{Conclusion}

In a first attempt to explore the gastronomic potential of seaweeds from local waters to provide umami flavouring in the New Nordic Cuisine, we have undertaken a systematic study of a small selection of brown and red seaweeds and compared their umami flavouring amino acid contents with those of the traditional Japanese soup broth dashi prepared from the large, brown Japanese seaweed konbu.

Although there is a documented, historical tradition of using seaweeds in the diet of some of the Nordic countries, in particular Iceland and Greenland, seaweeds are practically absent in traditional and modern Nordic cuisine [41]. With the rise of the New Nordic Cuisine and the efforts to use local foodstuff ingredients for a New Nordic Diet, many of them almost forgotten, we have focused in particular on two seaweed species: the red seaweed dulse (Palmaria palmata) and the brown seaweed sugar kelp (Saccharina latissima). Both of these species are available in large amounts in the wild in Nordic waters and can be farmed under controlled conditions. The wild resources can be harvested in a sustainable fashion, and, because they grow in the cold, pristine Nordic waters, the seaweeds are very clean and suitable for human consumption.

We have investigated the gastronomical potential of these seaweed species by focusing on the flavouring potential of simple water extracts, similarly to the Japanese dash $i$ that is the classic source of umami. Dashi owes its umami taste to the sodium salts of glutamic acid and aspartic acid, and any sweetness is predominantly due to free alanine. We have measured the concentration of these three amino acids in various extracts prepared under different well-controlled conditions, such as extraction temperature.

The main finding of the present work is that the use of well-controlled extraction techniques may release much more glutamate, aspartate and alaninate than the use of classic recipes involving cold-water soaking and subsequent heating in an open pan. Hence techniques involving extraction in a sealed plastic bag under vacuum pressure appear to have improved the extraction efficiency for free amino acids from seaweeds without compromising the flavour. Whereas the extraction temperature has a definite influence on the overall taste of the dashi, in particular the bitter notes developed at the higher temperatures, the amounts of glutamate, aspartate and alaninate appear to be little sensitive to whether the extraction temperature is $60^{\circ} \mathrm{C}$ or $100^{\circ} \mathrm{C}$. Similarly, we could not detect any significant dependence of water hardness on the amount of released umami-flavouring free amino acids.

We believe that the findings of the present study may be of use for improving recipes for making dashi, not least from konbu. Specifically, we found that whereas sugar kelp is a poor umami source, dulse is an excellent source with similar amounts of umami agents compared to Japanese dashi prepared from konbu in the classic 
way. Dashi from dulse also contains a significant amount of alaninate, which probably contributes to its mild, sweet taste.

The flavouring abilities of Nordic dulse dashi by its infusion in various dishes have been demonstrated in the case of three specific examples: ice cream with dulse infusion, fresh cheese infused with dulse and bread made from a sourdough infused with dulse. Subjective tasting experiments suggest that dulse is indeed an attractive flavouring agent and holds great promise for novel uses, not only in the New Nordic Cuisine but in general.

\section{Materials and methods}

\section{Seaweed cultivation and harvesting}

Sugar kelp (Saccharina latissima) was cultivated in the open coastal waters of Kattegat in Denmark. The sporophytes of sugar kelp are sawn on smaller ropes in a hatchery, and they attach to the rope with their holdfasts. The seeded and sprouted kelp ropes are fixed on cultivation longlines, cultivated for about 18 months and harvested when they reach a length of about $1.5 \mathrm{~m}$. The controlled cultivation produces high quality with nearly no fouling. The harvested kelp is sun-dried immediately after harvest.

Dulse (Palmaria palmata) and graceful red weed (Gracilaria verrucosa) were grown in open tanks (pools) fed with seawater and by using air turbulence to move the seaweeds, to provide nutrition and to facilitate photosynthesis. The dulse grows by making new proliferations and then building new main tissues. The controlled cultivation in pools not only enables a fouling-free quality but also facilitates a highly red pigmentation and large protein content. The harvested dulse and Gracilaria are sun-dried immediately after harvest.

\section{Commercial seaweed supplies}

Commercially available dried konbu was purchased in two different qualities: first-quality rausu-konbu from Sunaga village, Rausu District (Japan Fooding Ltd, London, UK) and second-quality hidaka-konbu from Hokkaido, Japan (Wakou Corp, Shiga, Japan). Commercially available dried dulse was purchased from Íslensk hollusta ehf (Reykjavik, Iceland). The dulse is hand-harvested from wild Icelandic resources and subsequently dried.

\section{Sous-vide water extracts from seaweeds}

Two types of water were used for seaweed extracts: ordinary tap water (Copenhagen, Denmark; water hardness = $20^{\circ} \mathrm{dH}$ ) and filtered, demineralised soft water. All extractions were based on $10 \mathrm{~g}$ of dry seaweed in $500 \mathrm{ml}$ of water placed in a plastic bag sealed under vacuum pressure (sous-vide) at $98.5 \mathrm{kPa}$ in a Komet Plus Vac 20 (KOMET Maschinenfabrik GmbH, Plochingen,
Germany) and immersed over a period of 45 minutes in a water bath at the prescribed constant extraction temperature.

\section{Sensory perception}

Because the present paper is not intended to be a quantitative study of the sensory perception of umami flavour in the seaweed extracts and the dishes flavoured by the extracts, we have not used a formal panel of professional tasters but employed a subjective and qualitative measure of taste sensation by integrating statements from experimenters and colleague chefs who are very experienced in evaluating and describing taste. The subjective analysis was carried out by a minimum of five qualified chefs who are considered trained tasters. In the case of the dulse ice cream, the tasting was part of a master's degree thesis on the complexity in food (Faculty of Life Sciences, University of Copenhagen, Copenhagen, Denmark) that was favourably received by a tasting panel of 60 persons. In addition, we registered responses from a large number of individual tasters on different occasions when the dulse-infused dishes were presented and tasted.

\section{Amino acid analysis}

All chemicals used were from Sigma-Aldrich (Copenhagen, Denmark) and of HPLC quality or better. Amino acid analysis was performed using the Biochrom 31+ Protein Hydrolysate System amino acid analyser (Biochrom, Cambridge, UK). Prior to analysis, proteins were precipitated by addition of trichloroacetic acid, and lipids were extracted with hexane. The amino acids were identified and quantified by comparison with pure amino acid standards with a major focus on glutamic acid, aspartic acid and alanine in their deprotonated states.

\section{Abbreviations \\ GMP: guanosine-5'-monophosphate (guanylate); IMP: inosine-5'- monophosphate (inosinate); MSA: monosodium aspartate (aspartate); MSG: monosodium glutamate (glutamate).}

\section{Acknowledgements}

Dr Kumiko Ninomiya is thanked for useful correspondence regarding dashi preparations, for information on umami flavour of soup broths, and for making available to us unpublished data on glutamate content in ichiban dashi. Prof Stefan Vogel is thanked for providing access to an HPLC installation and Prof Peter Højrup for help with the amino acid analysis. Masami Suenaga of Japan Fooding Ltd is gratefully acknowledged for help in purchasing rausu-konbu. MEMPHYS was supported as a centre of excellence by the Danish National Research Foundation for the period from 2001 to 2011. Nordic Food Lab is an independent institution fuelled by finances from external funds, private companies and foundations, including NordeaFonden, as well as from government sources. This work was supported by a grant (J.nr. 3414-09-02518) from the Danish Food Industry Agency.

\section{Author details}

${ }^{1}$ MEMPHYS, Center for Biomembrane Physics, Department of Physics, Chemistry, and Pharmacy, University of Southern Denmark, Campusvej 55, DK-5230 Odense M, Denmark, ogm@memphys.sdu.dk. ²Nordic Food Lab, 93 
Strandgade, DK-1401 Copenhagen K, Denmark, Iw@nordicfoodlab.org ${ }^{3}$ Restaurant Noma, 93 Strandgade, DK-1401 Copenhagen K, Denmark, marikultur@hotmail.com. Blue Food ApS, 2 Nordre Kaj, DK-8700 Horsens, Denmark, lad@memphys.sdu.dk.

\section{Authors' contributions}

OGM designed the study, suggested some of the pairing of ingredients for dashi production, took part in some of the dashi preparations, researched the literature on umami and composed and wrote the paper. LW designed procedures for optimal seaweed extraction to optimise umami flavour, designed the paring of ingredients for umami flavour, prepared dashi, exercised qualitative sensory evaluation of dashi and was a coinventor of dishes flavoured with dulse-based dashi. RB designed and implemented production facilities for seaweed farming in Denmark and harvested and processed the sugar kelp, dulse and Gracilaria used in this paper. LD set up and performed the amino acid analyses and processed the data.

\section{Competing interests}

The authors declare that they have no competing interests.

Received: 3 November 2011 Accepted: 21 March 2012

Published: 21 March 2012

\section{References}

1. Ikeda I: New seasonings. Chem Senses 2002, 27:847-849.

2. Yamaguchi S, Ninomiya K: What is umami? Food Rev Int 1998, 14:123-138.

3. Ninomiya K: Umami: a universal taste. Food Rev Int 2002, 18:23-38.

4. Kawamura Y, Kare M: Umami: A Basic Taste: Physiology, Biochemistry, Nutrition, Food Science New York: Marcel Dekker; 1986.

5. Proceedings of the 100th Anniversary Symposium of Umami Discovery: the roles of glutamate in taste, gastrointestinal function, metabolism, and physiology. Tokyo, Japan. September 11-13, 2008. In Am J Clin Nutr Edited by: Fernstrom JD 2009, 90(suppl):705S-885S.

6. Marcus JB: Culinary applications of umami. Food Technol 2005, 59:24-30.

7. Blumenthal H: The Fat Duck Cookbook London: Bloomsbury; 2008.

8. Barham P, Skibsted LH, Bredie WL, Frøst MB, Møller P, Risbo J, Snitkjaer P, Mortensen LM: Molecular gastronomy: a new emerging scientific discipline. Chem Rev 2010, 110:2313-2365.

9. Kasabian A, Kasabian D: The Fifth Taste: Cooking with Umami New York: Universe Publishing; 2005.

10. Blumenthal H, Barbot P, Matsushisa N, Mikuni K: Dashi and Umami: The Heart of Japanese Cuisine London: Eat-Japan, Cross Media Ltd; 2009.

11. Mouritsen OG, Styrbæk K: Umami: Gourmetaben og den femte smag Copenhagen: Nyt Nordisk Forlag Arnold Busck; 2011.

12. Ninomiya K: Natural occurrence. Food Rev Int 1998, 14:177-211.

13. Giacometti T: Free and bound glutamate in natural products. In Glutamic Acid: Advances in Biochemistry and Physiology. Edited by: Filer $L J \mathrm{Jr}$, Garattini S, Kare MR, Reynolds AW, Wurtmann RJ. New York: Raven; 1979:25-34.

14. Maga JA: Flavor potentiators. Crit Rev Food Sci Nutr 1993, 18:231-312.

15. Yamaguchi S, Ninomiya K: Umami and food palatability. J Nutr 2000, 130:921S-926S.

16. Yoshida Y: Umami taste and traditional seasonings. Food Rev Int 1998, 14:213-246.

17. Sano C: History of glutamate production. Am J Clin Nutr 2009, 90:728S-732S

18. O'Mahony M, Ishii R: A comparison of English and Japanese taste languages: Taste descriptive methodology, codability and the umami taste. Br J Psychol 1986, 77:161-174

19. Chandrashekar J, Hoon MA, Ryba NJ, Zucker CA: The receptors and cells for mammalian taste. Nature 2006, 444:288-294.

20. Fuke $S$, Ueda Y: Interactions between umami and other flavor characteristics. Trends Food Sci Technol 1996, 7:407-411.

21. Bachmanov A: Umami: Fifth taste? Flavor enhancer? Perfum Flavor 2010, 35:52-57.

22. Chaudhari N, Landin AM, Roper SD: A novel metabotropic glutamate receptor functions as a taste receptor. Nature Neurosci 2000, 3:113-119.

23. Kunishima N, Shimada Y, Tsuji Y, Sato T, Yamamoto M, Kumasaka T, Nakanishi S, Jingami H, Morikawa K: Structural basis of glutamate recognition by a dimeric metabotropic glutamate receptor. Nature 2000, 407:971-977.
24. Nelson G, Chandrashekar J, Moon MA, Feng L, Zhao G, Ryba NJ, Zucker CS: An amino-acid taste receptor. Nature 2002, 416:199-202.

25. Li X, Staszewski L, Xu H, Durick K, Zoller M, Adler E: Human receptors for sweet and umami taste. Proc Natl Acad Sci USA 2002, 99:4692-4696.

26. San Gabriel A, Uneyama H, Yoshie Y, Torii K: Cloning and characterization of a novel mGluR1 variant from vallate papillae that functions as a receptor for L-glutamate stimuli. Chem Senses 2005, 30:i25-i26.

27. Yasuo T, Kusuhara Y, Yasumatsu K, Ninomiya Y: Multiple receptor systems for glutamate detection in the taste organ. Biol Pharm Bull 2008, 31:1833-1837.

28. Jyotaki M, Shigemura N, Ninomiya Y: Multiple umami receptors and their variants in human and mice. J Health Sci 2009, 55:647-681.

29. Kuninaka A: Studies on taste of ribonucleic acid derivatives. J Agric Chem Soc Jpn 1960, 34:487-492

30. Kodama S: On a procedure for separating inosinic acid. J Tokyo Chem Soc 1913, 34:751-755.

31. Zhang FB, Klebansky B, Fine RM, Xu H, Pronin A, Liu H, Tachdjian C, Li X: Molecular mechanism for the umami taste synergism. Proc Natl Acad Sci USA 2008, 105:20930-20934.

32. Temussi PA: Sweet, bitter and umami receptors: a complex relationship. Trends Biochem Sci 2009, 34:296-302.

33. Tsuji A: Japanese Cooking: A Simple Art Tokyo: Kodansha; 1980.

34. Fujii M: The Enlightened Kitchen: Fresh Vegetable Dishes from the Temples of Japan Tokyo: Kodanska; 2005

35. Yamaguchi S: Basic properties of umami and its effects on food flavor. Food Rev Int 1998, 14:139-176.

36. Oruna-Concha MJ, Methven L, Blumenthal H, Young C, Mottram DS Differences in glutamic acid and 5'-ribonucleotide contents between flesh and pulp of tomatoes and the relationship with umami taste. J Agric Food Chem 2007, 55:5776-5780.

37. Kurihara K: Glutamate: from discovery as a food flavor to role as a basic taste. Am J Clin Nutr 2009, 90:719S-722S.

38. Mouritsen OG: Sushi: Food for the Eye, the Body \& the Soul New York: Springer; 2009.

39. Mouritsen OG: Tang: Grøntsager fra havet Copenhagen: Nyt Nordisk Forlag Arnold Busck; 2009.

40. Rhatigan P: The Irish Seaweed Kitchen Co Down, Ireland: Booklink; 2010

41. Mouritsen OG: The emerging science of gastrophysics and its application to the algal cuisine. Flavour 2012, 1:6.

42. Mouritsen OG, Vildgaard T, Westh S, Williams L: Nordisk dashi: Smagsdommerne på Nordic Food Lab. Gastro 2010, 51:72-75.

43. Redzepi R, Meyer C: Noma Nordic Cuisine Copenhagen: Politiken; 2006.

44. Redzepi R: Noma: Time and Place in Nordic Cuisine New York: Phaidon; 2010

45. Ozawa S, Miyano H, Kawai M, Sawa A, Ninomiya K, Mawatari K, Kuroda M: Changes of free amino acids during cooking process of chicken consommé. 2004, 322, (in Japanese) presented at the 58th Congress of Japanese Society for Nutrition and Food Science, Sendai, May 21-23.

46. Ozawa S, Miyano H, Kawai M, Sawa A, Ninomiya K, Mawatari K, Kuroda M: Changes of free amino acids during cooking process of Chinese chicken bouillon. 2005, 322, (in Japanese) presented at 59th Congress of Japanese Society for Nutrition and Food Science, Tokyo, May 13-15.

47. Bergeron $E$, Jolivet P: Quantitative determination of glutamate in Rhodophyceae (Chondrus crispus) and four Phaeophyceae (Fucus vesiculosos, Fucus serratus, Cystoseira elegans, Cystoseira barbata). J Appl Phycol 1991, 33:115-120.

doi:10.1186/2044-7248-1-4

Cite this article as: Mouritsen et al: Seaweeds for umami flavour in the New Nordic Cuisine. Flavour 2012 1:4 